\title{
EFFECT OF TWO ESSENTIAL OILS FROM THE ASTERACEAES FAMILY AGAINST ECTOMYELOIS CERATONIAE ZELL. (LEPIDOPTERA, PYRALIDAE): CASE OF ARTEMISIA HERBA-ALBA ASSO. AND ARTEMISIA COMPESTRIS L.
}

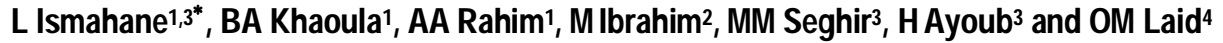 \\ ${ }^{1}$ Genetics, Biotechnology and Bioresources Valorization Laboratory; Department of Nature and Life Sciences, \\ Mohamed Kheider University, Biskra, Algeria \\ 2Desertification and Climate Team, Mechanics Laboratory, Department of Nature and Life Sciences, Faculty of Exact \\ Sciences and Sciences of Nature and Life, Amar Tlidji University, Laghouat, Algeria \\ ${ }^{3}$ Genetics, Biotechnology and Bioresources Valorization Laboratory; Department of Agronomy Sciences, Mohamed \\ Kheider University, Biskra, Algeria \\ ${ }^{4}$ Applied Neuro-Endocrinology Laboratory, Department of Nature and Life Sciences, Faculty of Exact Sciences and \\ Sciences of Nature and Life, Badji Mokhtar University, Annaba, Algeria
}

\begin{abstract}
The current work was done Artemisia herba-alba and Artemisia compestris essential oils harvested from the Eastern Algerian Sahara, their insecticidal characteristics against the eggs and adults of the date moth Ectomyelois ceratoniae. Indeed, two treatment modes were used; by contact application on eggs and by inhalation against adults. It appears from the results that the hatch rates were less than the hatching rate recorded in the control $(96 \% \pm 00.00)$. The hatching rate reported on eggs treated by the highest dose $(160 \mu \mathrm{l} / \mathrm{ml})$ of Artemisia herba-alba and Artemisia compestris essential oils are $16.66 \pm$ 08.81 and $37.77 \pm 13.47$ respectively. Statistical treatment results by the Chi-square test (X2), attest that the treatment by $A$. herba-alba and Artemisia compestris essential oils at the same dose $(160 \mu / \mathrm{ml})$ affect significantly $(X 2=35.62, p=0.00$ and $X 2=21.17, p=0.00$ respectively) the hatching rate compared to the control. The sensitivity of adults to essential oils is expressed by $100 \%$ mortality rates obtained after $10 \mathrm{~min}$ of treatment by the highest doses $(80 \mu \mathrm{l} / \mathrm{ml}$ and $160 \mu / \mathrm{ml})$ of $A$. herba-alba essential oils, the same mortality rates $(100 \%)$ were notified with the same doses ( $80 \mu \mathrm{l} / \mathrm{ml}$ and 160 $\mu / \mathrm{ml}$ ) after $20 \mathrm{~min}$ and $15 \mathrm{~min}$ of treatment by Artemisia compestris essential oils respectively. The dose-dependent mortality data revealed that there was a significant difference between the five doses of A. herba-alba essential oil tested except at the last treatment time $(20 \mathrm{~min})$ for which it was appeared $p$ $=0.571$, while for $A$. compestris essential oil, a significant difference was recorded with $p$ varying between 0.00 and 0.003 . The lowest $L_{50}$ value $(0.09 \mu \mathrm{l} / \mathrm{ml}$ and $16.71 \mu \mathrm{l} / \mathrm{ml})$ were noted during the longest treatment time $(20 \mathrm{~min})$, while the highest $\mathrm{LD}_{50}$ value $(75.85 \mu \mathrm{l} / \mathrm{ml}$ and $263.7 \mu \mathrm{l} / \mathrm{ml})$ were found during the shortest time ( $5 \mathrm{~min}$ ) of $A$. herba-alba and $A$. compestris respectively.
\end{abstract}

Key words: Artemisia compestris, Artemisia herba-alba, Date moth, Ectomyelois ceratoniae, Essential oils, Toxicity

\section{Introduction}

Among the various parasitic attacks and diseases that affect the date, the major problem for importers is the fruit infestation by the date moth. The moth lays eggs on the surface of ripe dates. The larva penetrates inside and leaves traces which waste the fruit and reduce its commercial value (Ordines 2000). The results of

*Author for correspondence: smahanlebbouz@yahoo.fr 
chemical control were disappointing to the extent that there is no reduction in the infection rate, this is explained by the endophytic behavior and hanging position of the fruit on the tree that does not facilitate the contact insecticide (Khoualdia et al. 1996, Grissa et al. 2011, Peyrovil et al. 2011, Azqandi et al. 2015). Moreover, oases are a fragile ecosystem where the use of pesticides would have secondary effects for both human being and the environment (Dhouibi 2000). Continuous attack of the pest, incapacity and defects of chemical control, obliges to orient towards other means less drastic and more environmentally compatible (Escoubet 2011). Biopesticides of plant origin are called the means for a better future, because demand for safe crop protection products of low persistence and qualified as "green products" are actually on the rise which ones based on essential oils can be the tools of choice in management programs of pest resistance to pesticides (Isman 2000). The development of new control methods by the use of plants or their extracts possessing insecticidal properties constitutes a concern of the present work. The objective of this study mainly focused on Artemisia herba-alba Asso. and Artemisia compestris L. (Asteraceaes) essential oils harvested from the eastern Algerian Sahara, their insecticidal characteristics against the eggs and adults of the date moth Ectomyelois ceratoniae.

\section{Material and Methods}

\section{Collection of plants}

The two plants studied were harvested during October 2017 from the Ain Zaatout (Biskra, Algeria) region. The samples were dried at umber, under laboratory ambient temperature for 21 days. After drying, only the leaves were recuperated and subjected to hydro distillation to obtain the essential oils.

\section{Extraction of essential oils}

The simplest method of extracting essential oils is hydro distillation. Its principle consists of immersing the plant material in a water bath, and then the whole is brought to boiling under atmospheric pressure (Sutour 2010). Leaves were subjected to hydro distillation using a modified Clevenger type apparatus.

\section{Animal rearing}

Animal materials are represented by the eggs and the adults of $E$. ceratoniae collected from a rearing colony culture initiated in the laboratory of National Institute of Plant Protection (Biskra, Algeria) under following conditions: (temperature of $27 \pm 2^{\circ} \mathrm{C}$, relative humidity of $65 \pm 10 \%$ ) and photoperiod (16:8) (L:D) (Al-Izzi et al. 1987). The choice of stages was justified because effective control of adults limits their fertility and therefore the number of eggs and the rate of infestation would be reduced.

\section{Toxicity tests}

Two treatment modes were used to test toxicity of Artemisia herba-alba Asso and Artemisia compestris L. essential oils; one by contact application on eggs and the other by inhalation against adults. The tests were carried out according to the protocol established by McDonald et al. (1970). Several pilot tests were carried out to select the doses to be used; the doses were prepared just prior to testing, by diluting the essential oil in tween 80 at a concentration of $0.1 \%$ which is non-toxic to insects (Bokobana et al. 2014). Thus, five doses were prepared $(10,20,40,80.160 \mu \mathrm{l} / \mathrm{ml})$ with a control (Tween 80 diluted at $0.1 \%)$. 


\section{Contact toxicity}

With a total of 90 eggs ( $24 \mathrm{~h}$ old) for each concentration (30 eggs/ petri dish), the eggs were sprayed directly by the prepared doses of Artemisia herba-alba Asso. essential oils. The control eggs were pulverized with diluted Tween $80(0.1 \%)$. After three days of incubation, the hatched eggs are counted by using binocular loupe during one week. The same protocol was followed for $A$. compestris $L$. essential oil.

\section{Inhalation toxicity}

With total of 30 adults $(24 \mathrm{~h}$ old) for each concentration bottle of $500 \mathrm{ml}$ capacity, served as fumigant chambers containing a piece of cotton soaked by Artemisia herba-alba Asso. essential oil, were introduced 10 adult. The control adults were introduced in the bottle containing cotton impregnated in diluted Tween 80 $(0.1 \%)$, the experiment was followed until death of all the treated adults. The same protocol was followed for Artemisia compestris L. essential oil.

\section{Calculation of hatching and mortality rate}

For eggs, the hatching rate was calculated using the following formula: The hatching rate $(\%)=($ number of eggs hatched / total number of eggs) $\times 100$. Adults mortality in treated bottles (M2) were expressed according to the Schneider-Orelli (1947) formula (Xu 2004) in corrected mortalities (Mc), taking into account naturals mortalities occurring in the control bottles (M1) using the following formula: Schneider-Orelli (1947) formula: $\mathrm{MC}=[\mathrm{M} 2-\mathrm{M} 1 / 100-\mathrm{M} 1] \times 100$.

\section{Statistical analyses}

To assimilate the effect of different concentrations of the essential oil against eggs hatching rate, the results are compared pair wise by the chi-square test (X2) using IBM SPSS statistics 22. Data of mortality rates reported by both the plants depending on the dose administered were subjected to one-way analysis of variance, then the means were compared using Tukey's test whether there were differences between the treatments at the $5 \%$ level of confidence. $R^{2}, L_{50}$ values were estimated by probit analysis using the same program.

\section{Results}

\section{Effect of $A$. herba-alba and $A$. compestris essential oils on $E$. ceratoniae eggs}

The results of the ovicidal effect of $A$. herba-alba and $A$. compestris essential oils on the hatching rate (\%) of E. ceratoniae treated eggs depending on the doses are shown in Table 1. It appears from the results of the two studied plants that whatever the treatment doses the hatch rates were found less than the hatching rate recorded in the control in the order of $96 \pm 00.00 \%$.

Hatching rates of $88.99 \pm 02.03 \% ; 83.33 \pm 00.00 \% ; 75.55 \pm 8.39 \% ; 49.99 \pm 8.81 \%$ and $16.66 \pm 8.81 \%$ have been reported on eggs treated with $A$. herba alba essential oils at concentrations 10, 20, 40, 80 and 160 $\mu / \mathrm{ml}$ respectively, with the same concentrations also for order of $A$. compestris essential oil, registered hatching rate were $85.55 \pm 1.92 \% ; 82.22 \pm 3.84 \% ; 73.33 \pm 3.33 ; 65.56 \pm 5.09 \%$ and $37.77 \pm 13.47 \%$ respectively (Table 1). 
Table 1. Hatching rate (\%) (Mean $\pm \mathrm{SD})$ of $E$. ceratoniae eggs treated with $A$. herba-alba and $A$. compestris essential oil

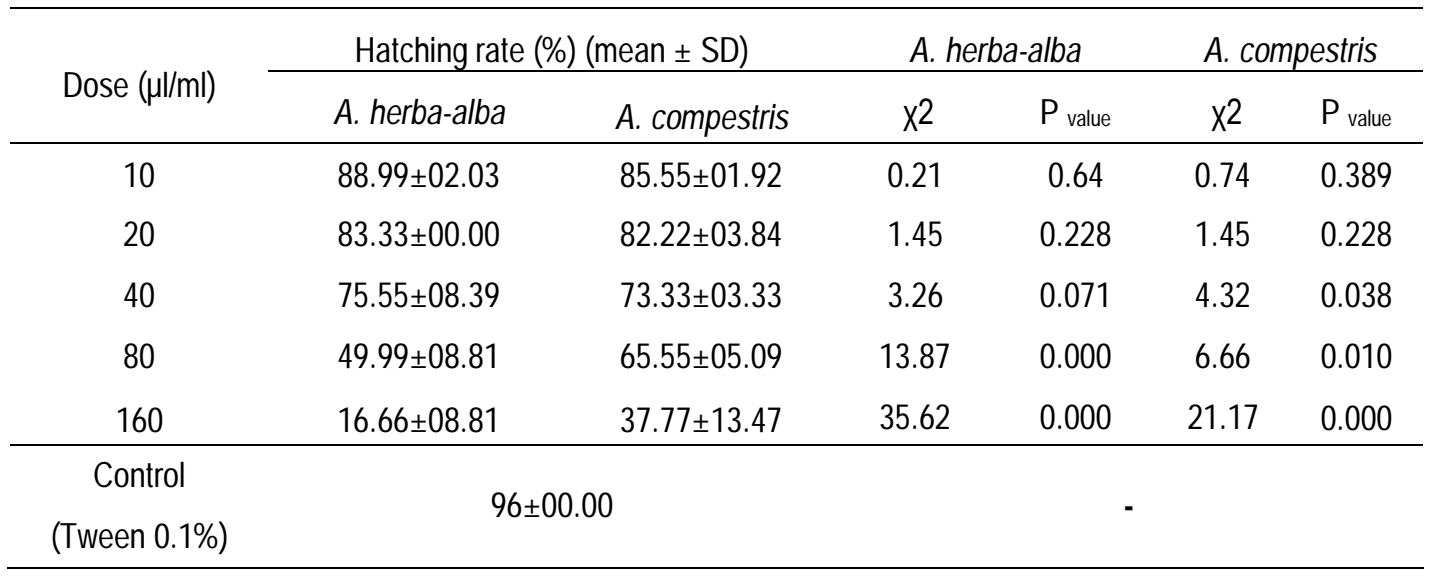

It should also be noted that the hatching rate decreases with increasing concentrations of both the plants essential oils (Table 1). The unhatched eggs treated with $A$. herba-alba essential oil have a dead embryo inside the egg while the unhatched eggs treated with $A$. compestris essential oil present deformity. Statistical analysis resulted by the chi-square test ( $\mathrm{X} 2$ ) (Table 1 ), attest that the treatment with $A$. herba-alba essential oils at the concentrations 10,20 , and $40 \mu \mathrm{l} / \mathrm{ml}$ do not significantly affect the eggs hatching compared to the control ( $x 2=0.21$ and $p=0.640, x 2=1.45$ and $p=0.228, x 2=3.26$ and $p=0.071$ respectively), on the other hand, with the high concentrations 80 and $160 \mu \mathrm{l} / \mathrm{ml}$, the hatching rate was significantly affected with $\chi^{2}=$ 13.87 and $p=0.000, x^{2}=35.62$ and $p=0.000$ respectively. Whilst $A$. compestris essential oil affect significantly the hatch rate starting at $40 \mu \mathrm{l} / \mathrm{ml}$ concentration with $\mathrm{X} 2=4.32$ and $p=0.038$.

\section{Action of $A$. herba-alba and $A$. compestris essential oils on $E$. ceratoniae adults}

The results on the effect of $A$. herba-alba and $A$. compestris essential oils on $E$. ceratoniae adults are presented in Table 2 and 3 respectively.

Table 2. Mortality rate (\%) (Mean $\pm \mathrm{SD})$ of $E$. ceratoniae adults treated with $A$. herba-alba essential oil

\begin{tabular}{ccccccc}
\hline \multirow{2}{*}{ Time $($ min. $)$} & \multicolumn{6}{c}{ Dose $(\mu / \mathrm{ml})$} \\
\cline { 2 - 7 } & 10 & 20 & 40 & 80 & 160 & $P_{\text {value }}$ \\
\hline 5 & $00.00 \pm 00.00_{\mathrm{a}}$ & $13.33 \pm 05.77_{\mathrm{b}}$ & $33.33 \pm 30.55_{\mathrm{ab}}$ & $36.66 \pm 05.7 \mathrm{~b}_{\mathrm{bc}}$ & $83.33 \pm 11.54_{\mathrm{c}}$ & 0.001 \\
10 & $26.66 \pm 11.54_{\mathrm{a}}$ & $70.00 \pm 10.00_{\mathrm{b}}$ & $80.00 \pm 26.45_{\mathrm{bc}}$ & $100.00 \pm 0.00_{\mathrm{c}}$ & $100.00 \pm 0.00_{\mathrm{c}}$ & 0.000 \\
15 & $83.33 \pm 05.77_{\mathrm{a}}$ & $96.66 \pm 05.77_{\mathrm{b}}$ & $100.00 \pm 0.00_{\mathrm{b}}$ & $100.00 \pm 0.00_{\mathrm{b}}$ & $100.00 \pm 0.00_{\mathrm{b}}$ & 0.001 \\
20 & $96.66 \pm 05.77_{\mathrm{a}}$ & $100.00 \pm 0.00_{\mathrm{a}}$ & $100.00 \pm 0.00_{\mathrm{a}}$ & $100.00 \pm 0.00_{\mathrm{a}}$ & $100.00 \pm 0.00_{\mathrm{a}}$ & 0.571 \\
\hline
\end{tabular}

Means in the same line with the same letter are not significantly different at $p \leq 0.05$. 
E. ceratoniae adult's treated with different doses of $A$. herba-alba essential oil, it occur that with the lowest dose $(10 \mu / \mathrm{ml})$, the highest mortality rate $(96.66 \pm 5.77)$ is obtained during the longest period of treatment and which is $20 \mathrm{~min}$ (Table 2). At half of this period (10 min), it was reported a mortality rate of $100 \%$ with the highest doses $(80$ and $160 \mu / / \mathrm{ml}$ ). During the same treatment period, the mortality rates are $70 \pm 10 \%$ recorded with the $20 \mu \mathrm{l} / \mathrm{ml}$ dose and $80 \pm 26.45 \%$ with the $40 \mu / \mathrm{ml}$ dose. No mortality is achieved for the control, whatever the duration of treatment. According to the results (Table 3 ) of adult's treatment with the $A$. compestris essential oils, it appears that the most important mortality recorded on adults treated with the lowest dose $(10 \mu / \mathrm{ml})$ was $10 \pm 10 \%$ after 20 min of treatment. During the same treatment period, maximum mortalities rates of $76.67 \pm 5.77$ and $90 \pm 10 \%$ were notified with the 20 and $40 \mu \mathrm{l} / \mathrm{ml}$ doses respectively. With high doses, 80 and $160 \mu / / \mathrm{ml}$, the mortality rates of $100 \%$ are recorded for 20 and 15 min respectively. No mortality is achieved for the control, whatever the duration of treatment (Table 2).

Table 3. Mortality rate (\%) (Mean \pm SD) of E. ceratoniae adults treated with $A$. compestris essential oil

\begin{tabular}{ccccccc}
\hline \multirow{2}{*}{ Time (min.) } & \multicolumn{6}{c}{ Dose $(\mu \mathrm{l} / \mathrm{ml})$} \\
\cline { 2 - 7 } & 10 & 20 & 40 & 80 & 160 & $\mathrm{P}_{\text {value }}$ \\
\hline 5 & $00.00 \pm 00.00_{\mathrm{a}}$ & $00.00 \pm 00.00_{\mathrm{a}}$ & $00.00 \pm 00.00_{\mathrm{a}}$ & $06.67 \pm 11.54_{\mathrm{a}}$ & $30.00 \pm 17.32_{\mathrm{b}}$ & 0.003 \\
10 & $00.00 \pm 00.00_{\mathrm{a}}$ & $00.00 \pm 00.00_{\mathrm{a}}$ & $13.33 \pm 23.09_{\mathrm{ab}}$ & $60.00 \pm 26.45_{\mathrm{bc}}$ & $80.00 \pm 20.00_{\mathrm{c}}$ & 0.001 \\
15 & $00.00 \pm 00.00_{\mathrm{a}}$ & $36.67 \pm 05.77_{\mathrm{b}}$ & $80.00 \pm 20.00_{\mathrm{bc}}$ & $90.00 \pm 10.00_{\mathrm{c}}$ & $100.0 \pm 00.00_{\mathrm{c}}$ & 0.000 \\
20 & $10.00 \pm 10.00_{\mathrm{a}}$ & $76.67 \pm 05.77_{\mathrm{b}}$ & $90.00 \pm 10.00_{\mathrm{bc}}$ & $100.0 \pm 00.00_{\mathrm{c}}$ & $100.0 \pm 00.00_{\mathrm{c}}$ & 0.000 \\
\hline
\end{tabular}

Means in the same line with the same letter are not significantly different at $p \leq 0.05$.

The results of statistical analyses of the dose-dependent mortality data revealed that there is a significant difference between the five doses of $A$. herba-alba essential oils tested except at the last treatment time (20 min) for which we was reported a $p=0.571$ (Table 2), while for $A$. compestris essential oil, a significant difference was recorded between the five doses tested for all the treatment times with $p$ varying between 0.00 and 0.003 (Table 3). The discrimination of the means by the Tukey test at the significance level of $5 \%$ proves that $A$. herba-alba essential oils have an identical activity at the different doses after 20 min of exposure to the treatment (Table 2). On the other hand, the treatment with $A$. compestris essential oils for 20 min permits distinguished four homogeneous groups; group "a" contains the first dose $(10 \mu / \mathrm{ml})$, group "b" contains the second dose $20 \mu / \mathrm{ml})$, group "bc" includes the third dose $(40 \mu / \mathrm{ml})$ and group "c" which regroups the fourth $(80 \mu / / \mathrm{ml})$ and fifth dose $(160 \mu / \mathrm{ml})$ (Table 3).

$\mathrm{LD}_{50}$ of essential oils tested: The results of calculated lethal doses $50\left(\mathrm{LD}_{50}\right)$ are presented in Table 4, the essential oils of the plants studied become more effective when the exposure duration to the treatment increases. 
Table 4. Toxicological parameter of $A$. herba-alba and A. compestris effect on $E$. ceatoniae adults (y: probits of mortality rates, $x$ : decimal logarithm of concentrations)

\begin{tabular}{|c|c|c|c|c|}
\hline \multicolumn{5}{|c|}{ A. herba-alba } \\
\hline Time (min.) & Regression equation & $\mathrm{R}^{2}$ & $\mathrm{LD}_{50}(\mu \mathrm{l} / \mathrm{ml})$ & $P_{\text {value }}$ \\
\hline 5 & $Y=4.23 X-2.95$ & 0.78 & 75.85 & 0.044 \\
\hline 10 & $Y=4.29 X-0.43$ & 0.88 & 18.00 & 0.016 \\
\hline 15 & $Y=2.46 X+3.84$ & 0.80 & 2.95 & 0.041 \\
\hline 20 & $Y=1.26 X+6.32$ & 0.50 & 0.09 & 0.182 \\
\hline \multicolumn{5}{|c|}{ A. compestris } \\
\hline Time (min.) & Regression equation & $\mathrm{R}^{2}$ & $\mathrm{LD}_{50}(\mu \mathrm{l} / \mathrm{ml})$ & $P_{\text {value }}$ \\
\hline 5 & $Y=4.14 X-5.04$ & 0.79 & 263.70 & 0.043 \\
\hline 10 & $Y=5.64 X-6.03$ & 0.89 & 90.13 & 0.014 \\
\hline 15 & $Y=6.35 X-5.07$ & 0.88 & 38.40 & 0.018 \\
\hline 20 & $Y=4.33 X-0.92$ & 0.93 & 16.71 & 0.008 \\
\hline
\end{tabular}

The $L D_{50}$ values are inversely proportional to the treatment times. The lowest $L_{50}(0.09$ and $16.71 \mu / / \mathrm{ml})$ were noted during the longest treatment time $(20 \mathrm{~min}$.$) , while the highest L_{50}(75.85$ and $263.7 \mu / \mathrm{ml})$ are found during the shortest treatment time ( $5 \mathrm{~min}$.) by the essential oils of $A$. herba-alba and A. compestris respectively. Probit analysis proves that there is a significant correlation between mortality rate and the dose of treatment with $A$. herba-alba and $A$. compestris oils (Table 4).

\section{Discussion}

The results prove that essential oils extracted from $A$. herba-alba and $A$. compestris have insecticidal properties which on one hand lead a reduction in hatchability and also exert a lethal effect on adults. Previous studies demonstrate that $A$. herba-alba and $A$. compestris have very important insecticidal activity such as study of Ben Chaaban et al. (2019), showed that fumigant toxicity of $A$. herba-alba essential oil depending on concentration and exposure time. The exposure to vapors of $A$. herba-alba essential oil caused $0 \%$ of hatching rate of $E$. ceratoniae eggs at the concentration of $150 \mu / / /$ air during $48 \mathrm{~h}$, the same concentration lead $94 \%$ mortality of adults after $24 \mathrm{~h}$ with $\mathrm{LC}_{50}$ of $0.3 \mu \mathrm{l} / \mathrm{l}$ air. Delmi et al. (2013), after submission of Ephestia kuehnilla (Lepidoptera) adults at various doses of $A$. herba-alba essential oil reduced a significant mortality compared with control according to the dose and duration of exposure. In addition, disruption of adults' reproduction by extending the preoviposition period and reducing the period for depositing eggs as fertilized females couldn't who can't live more than one or two days, reduces the number of eggs deposited. A. herba-alba essential oil inhibits completely the fertility of Tineola bisselleilla (Lepidoptera) from $3 \mu \mathrm{l}$ dose. This oil, causes mortality rate of $100 \%$ with the dose of $2 \mu \mathrm{l}$ after four days of treatment with the LD50 was $1.25 \mu l$ (Bouchikhi et al. 2010). Hannour et al. (2016) demonstrate that $A$. herbaalba essential oil passed ovicidal and adulticidal effect against Phthorimaea operculella (Lepidoptera). The LD ${ }_{50}$ for eggs was $39.54 \mu \mathrm{l} / \mathrm{l}$ airs, lethal concentrations ranged from 39.33 to $6.80 \mu / / /$ air among adult males 
and from 39.72 to $6.39 \mu \mathrm{l} / \mathrm{l}$ air among adult females. A. herba-alba essential oils showed a nematicidal activity toward Meloidogyne incognita and this activity increases with the concentration and the period of exposure. Thus, the high dose $(800 \mu / / /)$ inhibits the hatching of eggs by $62.8 \%$ after 12 days of treatment (Sellami et al. 2010). The acridicide test revealed that $A$. herba-alba essential oil proved effective against Schistocerca gregaria adults for which a mortality rate of $100 \%$ was reached on the $16^{\text {th }}$ day with the highest dose $(0.1 \mu \mathrm{g} / \mathrm{g})$ (Figuigui et al. 2014). There are few studies that have investigated the insecticidal effect of $A$. compestris essential oil compared to A. herba-alba essential oil. According to Al-Harbi et al. (2021) the high doses (8 and $16 \mu / / \mathrm{ml}$ ) of $A$. compestris essential oils applied by inhalation on the rice weevil adults (Sitophilus oryzae) provokes mortality rates of $100 \%$ after $48 \mathrm{~h}$. The $\mathrm{LD}_{50}$ was $10.59 \mathrm{~h}$ for the highest dose $(16 \mu / / \mathrm{ml})$. The essential oil from $A$. campestris, containing $\beta$-pinene (15.2\%), a-pinene (11.2\%), myrcene $(10.3 \%)$, germacrene $D(9.0 \%)(Z)-\beta$-ocimene $(8.1 \%)$ and $y$-curcumene (6.4\%), showed remarkable toxicity against Culex quinquefasciatus ( $\left(\mathrm{C}_{50}\right.$ of $\left.45.8 \mathrm{mg} / \mathrm{l}\right)$ and moderate effects $\left(\mathrm{LD}_{50}\right.$ of $\left.99.8 \mu \mathrm{g} / \mathrm{adult}\right)$ against Musca domestica (Sassoui et al. 2020). The ovicidal and adulticidal effect of essential oils against $E$. ceratoniae has been proven by several studies including the study of Ben Abada et al. (2020), showing that Rosmarinus officinalis essential oils inhibits adult emergence with inhibition rates ranged between $22 \%$ and 100\%. Lebbouz et al. (2016), report that Peganum harmala essential oils have an ovicidal and adulticidal effects against $E$. ceratoniae, which reflected by decreasing of hatching rate to $5.65 \%$ compared to the control which is $87.35 \%$ and causes $100 \%$ mortality after 5 days of treatment of $E$. ceratoniae adults with a $\mathrm{LT}_{50}$ of 1.45 days. Amri et al. (2014), indicate that the topic aplication of Thymus capitalus essential oils induced at the dose of $8 \mu / \mathrm{ml}$ causes $100 \%$ mortality of $E$. ceratoniae adults after $24 \mathrm{~h}$ exposure. As stated by Bachrouch et al. (2010), the highest concentration (136 $\mu / / \mathrm{l}$ air) of Pistacia lentiscus essential oils induces $100 \%$ mortality after $48 \mathrm{~h}$ exposure, the corresponding $\mathrm{LC}_{50}$ was $40.2 \mu / / \mathrm{l}$ air. The fecundity and hatching rates decreased with increases in concentration or exposure time to the oil, at the concentration of $136 \mu / / /$ air, fecundity and hatching rates were respectively 35 eggs/ female and $42.86 \%$ adds Bachrouch et al. (2010). Haouel et al. (2010), showed that Eucalyptus rudis essential oils achieved $100 \%$ mortality of $E$. ceratoniae adults treated by fumigation after $12 \mathrm{~h}$ of treatment. The $L T 50$ was $36.10 \mathrm{~h}$.

The toxicity of essential oil is related to their compositions in oxygenated mono terpenes which are major compounds and which prove an insecticidal activity against different species of insects (Papachristos and Stamopoulos 2002). However, Deletre et al. (2014), have shown that the biological effect of an essential oil is not always due only to the activity of the major compound. Indeed, synergistic effects can occur between major and/or minor compounds, suggesting that the mechanisms of action are different. In general, essential oils reduce the phytophagous insect populations by a double action: inhalation toxicity exerted on the adults as well as an inhibition of the reproduction (Regnault- Roger and Hamraoui 1997).

\section{Conclusion}

The result shows that $A$. herba-alba and $A$. compestris essential oils have an ovicidal and adulticidal effects aginst $E$. ceratoniae. They could be good bio-insecticide alternatives to chemical control, while preserving human health and the environment. These new molecules are biodegradable and less likely to cause the resistance of the target species. 


\section{References}

Al Figuigui J, Benjelloun M, Elghadraoui L and Zaim A (2014). Effet acridicide de deux plantes aromatiques et médicinales sur la survie des adultes de Schistocerca gregaria. Dixième conférence internationale sur les ravageurs en agriculture. Montpellier, pp.11.

Al-Harbi NA, Al Attar NM, Hikal DM, Mohamed SE, Latef AAH, Ibrahim AA and Abdein MA (2021). Evaluation of insecticidal effects of plants essential oils extracted from basil, black seedsand lavender against Sitophilus oryzae.Plants, $10: 829$, https://doi.org/10.3390/plants10050829.

Al-Izzi MAJ, Al-Maliky SK and Jabbo NF (1987). Culturing the carob moth, Ectomyelois ceratoniae (Zeller) (Lepidoptera, Pyralidae), on an artificial diet. Journal of Economic Entomology, 80: 277-280.

Amri I, Hamrouni L, Mohsen H, Jamoussi B and Lebdi K (2014). Essential oils as biological alternatives to protect date palm (Phoenix dactylifera L.) against Ectomyelois ceratoniae Zeller (Lepidoptera, Pyralidae), Chilean Journal of Agricultural Research, 74: 273-279.

Azqandi RS, Kazazi M and Abdulahadi F (2015). Ectomyelois ceratoniae Zeller (Lepidoptera, Pyralidae) and its control procedures in Iran. Journal of Asian Business and Economics Studies, 05: 743-747.

Bachrouch O, Mediouni Ben Jemaa J, Wissem AW, Talou T, Marzouk B and Abderraba M (2010). Composition and insecticidal activity of essential oil from Pistacia lentiscus L. against Ectomyelois ceratoniae Zeller and Ephestia kuehniella Zeller (Lepidoptera, pyralidae). Journal of Stored Products Research, 6: 242-247.

Ben Abada M, Haouel Hamdi S, Masseoud C, Jroud H, Bousshih E and Mediouni Ben Jemâa J (2020). Variations in chemotypes patterns of Tunisian Rosmarinus officinalis essential oils and applications for controlling the date moth Ectomyelois ceratoniae (Pyralidae). South African Journal of Botany, 128: 18-27.

Ben Chaaban S, Mnaffed A, Mahjoubi K and Mediouni Ben Jemaa J (2019). Efficacy of Essential Oils to Control the Carob Moth, Ectomyelois ceratoniae Zeller (Lepidoptera: Pyralidae). International Journal of Agriculture Innovations and Research, 7: 388-391.

Bokobana EM, Koba K, Poutouli WP, Akantetou PK, Nadio NA, Laba B, Tozoou P, Raynaud C and Sanda K (2014). Evaluation du potentiel insecticide et repulsif de l'huile essentielle de Cymbopogon schoenanthus (I.) spreng. Sur Aphis gossypii glover (Homoptera, Aphididae), ravageur du cotonnier au Togo. Science De La Vie, De La Terre et Agronomie, Rev. CAMES 2(2): 48-55.

Bouchikhi Tani Z, Bendahou1 M and Khelil MA (2010). Lutte contre la bruche Acanthoscelides obtectus et la mite Tineola bisselliella par les huiles essentielles extraites de deux plantes aromatiques d'Algérie. Lebanese Science Journal, 11: 55-68.

Deletre E, Chandre F, Menut C and Martin T (2014). Bioactive natural compound against whitefly Bemisia tabaci. $2^{\text {nd }}$ International Conference on Pests in Agriculture, Montpellier, pp. 11.

Delimi A, Taibi F, Fissah A, Gherib S, Bouhkari M and Cheffrour A (2013). Bio-activité des huiles essentielles de l'Armoise blanche Artemessia herba-alba: effet sur la reproduction et la mortalité des adultes d'un ravageur des denrées stockées Ephestia kuehniella (Lepidoptera). Afrique Science, 09: 82-90.

Dhouibi MH (2000). Lutte intégrée pour la protection du palmier dattier en Tunisie. Ed centre de publication universitaire, Tunisie, pp. 1-134.

Escoubet $P$ (2011). Les limites de la lutte chimique. Les ravageurs de nos jardins. Journée Biologique du Parc Phoenix. Nice, Memories of the Oceanographic Institute Paul Ricard, pp. 59-72.

Grissa LK, Mejri O and Ben Brahim H (2011). Effect of diapause for improving mass-rearing and field performance of irradiated carob moth, Ectomyelois ceratoniae Zeller (Lepidoptera, Pyralidae), in Tunisia. Increasing the efficiency of Lepidoptera sit by enhanced quality control, Vienna, pp. 35-37. 
Hannour K, Boughdad A, Maataoui A and Bouchelta A (2016). Fumigant toxicity of Artemisia herba-alba essential oil against the insect Phthorimaea operculella (Zeller 1873) (Lepidoptera, Gelechiinae). Conférence: 2ème Congrès International de l'AJC: Substances Naturelles et Développement Durable, Rabat, pp. 2.

Houal S, Mediouni Ben Jemaa J and Khouja ML (2010). Postharvest control of date moth Ectomyelois ceratoniae using Eucalyptus essential oil fumigation. Tunisian Journal of Plant Protection, 05: 201-212.

Isman M (2000). Plant essential oils for pest and disease management. Crop Protection, 19: 603-608.

Jemaa JMB, Fukova I, Frydrychova R, Dhouibi MH and Marec F (2004). Karyotype, sex chromatin and sex chromosome differentiation in the carob moth, Ectomyelois ceratoniae (Lepidoptera: Pyralidae). Caryologia, 57: 184-194.

Khoualdia O, Jarraya A, Rhouma A, Marro JP and Brun J (1996). Use of Trichogramma cacoeciae Marchal (Hym.: Trichogrammatidae) against the date moth. National Institute of Agricultural Research of Tunisia, 69: 197-205.

Lebbouz I, Mehaoua MS, Merabti I, Bessahraoui Kh and Ouakid ML (2016). Ovicidal, larvicidal and adulticidal activities of essential oils from Peganum harmala L. (Zygophyllacae) against date moth Ectomyelois ceratoniae Zeller (Lepidoptera, Pyralidae). International Journal of Biosciences, 08: 146-152.

McDonaldL L, Guy RH and Speirs RD (1970). Preliminary evaluation of new candidate materials as toxicants, repellents and attractants against stored product insect, Agriculture Research Services, Washington DC, USA.

Ordines B (2000). Study of the main European markets for date and commercial potential of non-traditional varieties. FAO (Ed.), pp. 1-66.

Papachristos DP and Stamopoulos DC (2002). Repellent, toxic and reproduction inhibitory effect of essential oil vapours on Acanthoscelides obtectus (Say) (Coleoptera), a bruchid of kidney bean (Phaseolus vulgaris L.). Journal of Stored Products Research, 31: 291-299.

Peyrovi1 M, Goldansaz SH and Jahromi KT (2011). Using Ferula assafoetida essential oil as adult carob moth repellent in Qom pomegranate orchards (Iran). African Journal of Biotechnology, 10: 380-385.

Regnault-Roger C and Hamraoui A (1997). Control of phytophagous insects by aromatics plants and their allelochimical molecules. Acta Botanica Gallica, 144: 401- 412.

Sassoui A, Hendel N, Sarri D, Sarri M, Filippo M, Maurizio B, Donato R., Angelo C, Roman P and Giovanni B (2020). Essential oils from three Algerian medicinal plants (Artemisia campestris, Pulicaria arabica, and Saccocalyx satureioides) as new botanical insecticides?. Environnemental Science and Pollution Research, 27: 26594-26604.

Schneider-Orelli O (1947). Entomologisches Praktikum: Einführung in die land-und forstwirtschaftliche Insektenkunde. Sauerländer Aarau.

Sellami S, Mezrket A and Dahmane T (2010). Activité nématicide de quelques huiles essentielles contre Meloidogyne incognita. Nematologia. Mediterranae, 38: 195-201.

Sutour S (2010). Chemical composition of essential oils and extracts of Corsican mint and kumquats. PhD thesis, University of Corsica Pascal Paoli, France.

Xu XN (2004). Combined releases of predators for biological control of spider mites Tetranychus urticae Koch and western flower thrips Frankliniella occidentalis (pergande), Cuvillie verlag Göttingen, Germany, pp. 1-109. 